\title{
Reporte de un caso de tratamiento de gastroparesia pediátrica con prucaloprida: una terapia novedosa
} A case report of prucalopride treatment in pediatric gastroparesis: a novel therapy

\author{
Diana P. Escobar-Serna ${ }^{a, b}$ (D), Fernando J. Peralta-Palmezano ${ }^{(\mathbb{D}}$, Juan J. Peralta-Palmezano ${ }^{a, b}$ (D)
}

\begin{abstract}
RESUMEN
La prucaloprida acelera el vaciamiento gástrico en adultos con gastroparesia. No existen estudios con este medicamento en niños con gastroparesia. Se presenta un niño de 8 años que consultó por síntomas posprandiales de un mes de duración, con diagnóstico de gastroparesia por gammagrafía de vaciamiento gástrico. No mejoró con metoclopramida, domperidona, eritromicina y esomeprazol. Recibió prucaloprida durante dos períodos (durante 178 y 376 días) a dosis de 0,03-0,04 mg / kg/ día. Presentó mejoría en el seguimiento con el índice cardinal de síntomas de gastroparesia y gammagrafías de vaciamiento gástrico. Por la buena respuesta, la prucaloprida podría ser una opción terapéutica en la gastroparesia pediátrica.

Palabras clave: gastroparesia, receptores de serotonina, agonistas del receptor 5-HT4, vaciamiento gástrico, imágenes con radionúclidos.
\end{abstract}

http: / / dx.doi.org/10.5546/ aap.2022.e98

Texto completo en inglés

http: / / dx.doi.org / 10.5546/ aap.2022.eng.e98

Cómo citar: Escobar-Serna DP, Peralta-Palmezano FJ, PeraltaPalmezano JJ. Reporte de un caso de tratamiento de gastroparesia pediátrica con prucaloprida: una terapia novedosa. Arch Argent Pediatr 2022;120(2):e98-e101. a. Departamento de Pediatría, Universidad Nacional de Colombia, Bogotá, Colombia.

b. Departamento de Pediatría, HOMI-Fundación Hospital Pediátrico la Misericordia, Bogotá, Colombia.

c. Departamento de Ginecología y Obstetricia, Universidad de Antioquia, Medellín, Colombia.

Correspondencia:

Juan J. Peralta-Palmezano: jjperaltap@unal.edu.co

Financiamiento: Ninguno.

Conflicto de intereses: Ninguno que declarar.

Recibido: 19-6-2021

Aceptado: 7-9-2021

\section{INTRODUCCIÓN}

La gastroparesia es un retardo del vaciamiento gástrico sin una obstrucción mecánica. Se manifiesta con vómitos, dolor abdominal, náuseas, saciedad temprana y distensión abdominal. ${ }^{1,2}$ Sus principales causas son idiopáticas, medicamentosas, posquirúrgicas, posvirales y la diabetes. ${ }^{2}$

Los medicamentos que actúan sobre los receptores de 5-hidroxitriptamina (5HT) son alternativas para el tratamiento de la gastroparesia. Dos agonistas de $5-\mathrm{HT}_{4}$ no selectivos, la cisaprida y el tegaserod, aceleran el vaciamiento gástrico. No se recomiendan por prolongación del intervalo QT e isquemia miocárdica, mientras que no se han reportado estos efectos adversos con los agonistas selectivos del receptor $5-\mathrm{HT}_{4}{ }^{3}$

La prucaloprida es un derivado de benzofurano y un agonista específico del receptor $5-\mathrm{HT}_{4}$. En niños tiene una rápida absorción oral, con concentración plasmática máxima alcanzada 2 horas después de la ingesta, con distribución rápida, una unión a proteínas plasmáticas del 28,6 \% y una semivida de eliminación de 19 horas. ${ }^{4}$ En adultos sanos y estreñidos, la prucaloprida acelera el vaciamiento gástrico y el tránsito del intestino delgado. ${ }^{5,6}$ Demostró ser un medicamento seguro en niños y adultos, con efectos adversos leves y transitorios (dolor abdominal, cefalea, incontinencia fecal, náuseas, flatulencia). ${ }^{4-6}$ Cuando se administró durante 4 semanas en adultos con gastroparesia, acortó los tiempos de vaciamiento gástrico de sólidos y mejoró la gravedad de los síntomas, con pocos efectos adversos. ${ }^{7}$ No hay estudios con este medicamento para los niños con gastroparesia.

El índice de síntomas cardinales de gastroparesia (GCSI, por su sigla en inglés) puede ser útil para monitorear la respuesta al tratamiento, ${ }^{8}$ con una buena comprensión de la mayoría de los términos por los niños. ${ }^{9}$ Evalúa tres grupos de síntomas: náuseas y vómitos, llenura posprandial y saciedad temprana, e hinchazón. La puntuación se calcula como el promedio de todas las puntuaciones de las 
subescalas (cada puntuación de la subescala se calcula promediando los elementos dentro de esta); las puntuaciones varían de 0 (ninguna) a 5 (muy grave) ${ }^{8}$

Se presenta el caso de un niño con gastroparesia tratado con prucaloprida, con un seguimiento prolongado con gammagrafía de vaciamiento gástrico y el GCSI.

\section{REPORTE DEL CASO}

Un niño de 8 años consultó por un mes de dolor abdominal en epigastrio y mesogastrio, saciedad temprana, distensión posprandial, regurgitación, estreñimiento y vómitos. Tenía antecedente de estreñimiento funcional desde el año de vida, medicado en ocasiones con polietilenglicol sin electrolitos. El hemograma, los niveles séricos de electrolitos y la proteína $C$ reactiva eran normales. La radiografía de abdomen mostró signos de estreñimiento.

Se hospitalizó para tratamiento con líquidos intravenosos, analgésicos, esomeprazol y polietilenglicol sin electrolitos. Los vómitos mejoraron, pero persistió con saciedad temprana, distensión abdominal, náuseas posprandiales y estreñimiento. Las gammagrafías de vaciamiento gástrico líquido y sólido diagnosticaron una gastroparesia (Tabla 1). Se evaluó la causa de la gastroparesia con radiografía de vías digestivas altas, esofagogastroduodenoscopia, glucemia, función tiroidea, ecografía abdominal, inmunoglobulinas séricas, transaminasas, bilirrubinas, nitrógeno ureico en sangre, creatinina, electrolitos, triglicéridos, colesterol, anticuerpos antitransglutaminasa tisular inmunoglobulina A, vitamina $\mathrm{E}$, vitamina $\mathrm{D}_{3}$, homocisteína, amonio, lactato/ piruvato, audiometría, ecocardiograma y electrocardiograma, todos con resultados normales. La biopsia de estómago mostró gastritis crónica no atrófica, sin alteraciones en el esófago ni en el duodeno.

El paciente recibió para la gastroparesia domperidona, eritromicina y metoclopramida. Se cambiaron los medicamentos por no haber ninguna mejoría de los síntomas. Para la gastritis, recibió esomeprazol. Para la constipación, recibió polietilenglicol sin electrolitos y, por persistencia de deposiciones de tipo Bristol 1 y 2, se adicionó picosulfato de sodio. En la Tabla 2 se describen las dosis y el tiempo de tratamiento.

Durante la hospitalización el paciente persistía con hiporexia, con pérdida de $2,5 \mathrm{~kg}$ a los 40 días de hospitalización. Requirió nutrición parenteral durante 20 días. El seguimiento nutricional se describe en la Tabla 3. El día 42 de hospitalización, considerando que no hubo mejoría de los síntomas (GCSI de 2,7) y con el consentimiento de los padres, se inició prucaloprida (dosis: $0,04 \mathrm{mg} / \mathrm{kg} /$ día), suspendiendo los otros laxantes y procinéticos. El día 10 con prucaloprida se realizó hemograma, electrolitos, transaminasas,

TABLA 1. Resultados de la gammagrafía de vaciamiento gástrico de líquidos y sólidos, y puntuaciones del índice de sintomas cardinales de gastroparesia

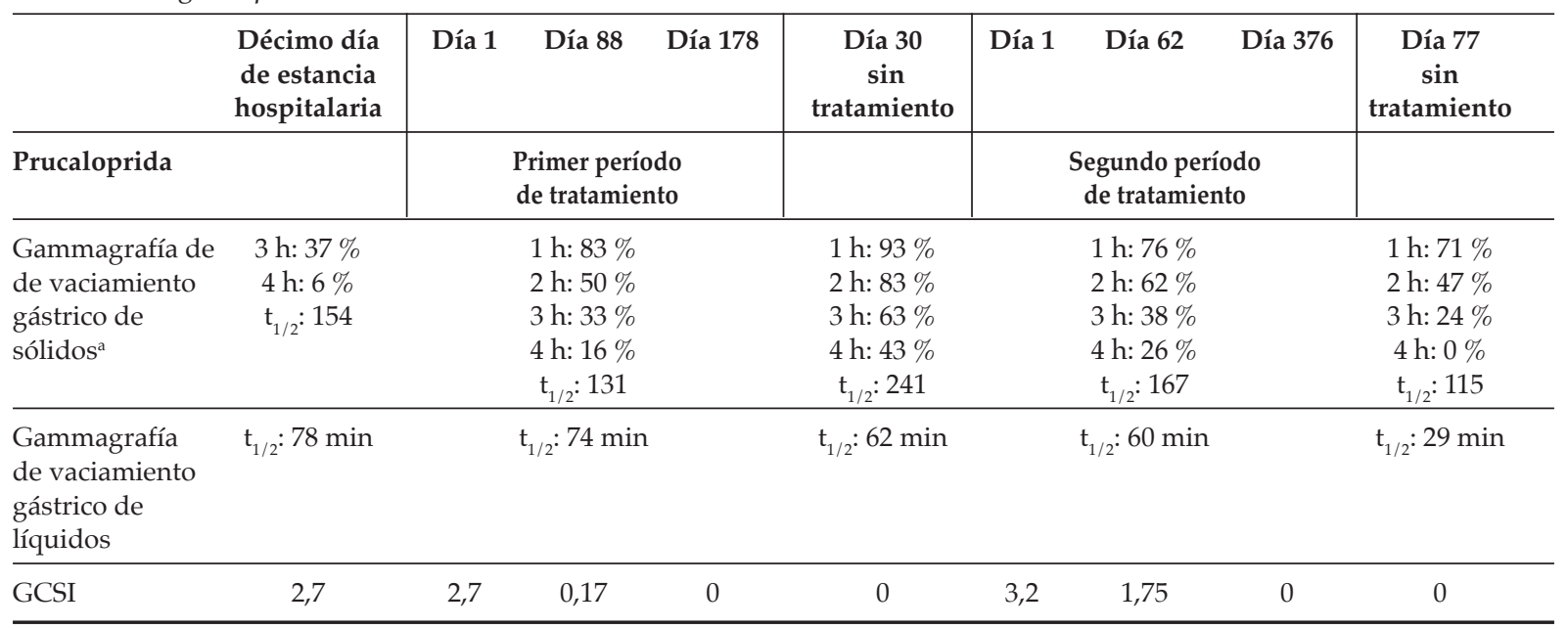

GCSI: el índice de síntomas cardinales de gastroparesia (por su sigla en inglés) (las puntuaciones varían de 0 [ninguna o ausente] a 5 [muy grave]); $\mathrm{t}_{1 / 2}$ : tiempo medio de vaciado gástrico medido en minutos (valor normal de $\mathrm{t}_{1 / 2}$ para sólidos: 132 minutos).

a Porcentaje de retención de radiomarcador (valores normales: $1 \mathrm{~h}<90 \%, 2 \mathrm{~h}<60 \%, 3 \mathrm{~h}<30 \%$ y $4 \mathrm{~h}<10 \%$ ). 
bilirrubina, nitrógeno ureico en sangre, creatinina, triglicéridos, colesterol total y electrocardiograma, con resultados normales. A los 18 días con prucaloprida sus síntomas mejoraron con un GCSI de 0,75. El día 20 presentó un dolor abdominal tipo cólico, con radiografía y ecografía abdominal sin alteraciones. Debido al dolor persistente, se redujo la dosis de prucaloprida a $0,03 \mathrm{mg} / \mathrm{kg} /$ día. El dolor abdominal mejoró después de 5 días de la reducción de la dosis, (GCSI de 0,4). Se otorgó el alta con prucaloprida y esomeprazol.

En el seguimiento ambulatorio, a los 71 días con prucaloprida se realizó un hemograma, transaminasas, albúmina, bilirrubina y electrolitos, con resultados normales. El día 88 se realizó una segunda gammagrafía de vaciamiento gástrico (Tabla 1). El día 178 y con un GCSI de 0, se suspendió la prucaloprida y el esomeprazol. Un mes después de suspender la prucaloprida, se realizó una tercera gammagrafía (Tabla 1).

El paciente permaneció asintomático durante 56 días, luego de los cuales presentó un cuadro de recidiva de dolor abdominal, estreñimiento, regurgitación, náuseas, vómitos y un GCSI de 3,2. Se inició un segundo período con prucaloprida (dosis: 0,03 mg/kg/día) y tras 16 días de tratamiento tenía un GCSI de 2,2. El día 43, debido a la persistencia de los síntomas posprandiales, se aumentó la dosis de prucaloprida a 0,04 mg/ kg/ día. El día 62 se realizó una cuarta gammagrafía (Tabla 1). El día 82 persistía con un GCSI de 1,75 , por lo que se suspendió esomeprazol. Los días 108 y 152 mejoraron los GCSI, con 0,75 y 0,3 respectivamente. En total recibió 376 días de prucaloprida (dosis: 0,04 mg/ kg/día), con un GCSI de 0, con deposiciones diarias, ganancia de peso y electrocardiograma normal. A los 77 días de seguimiento sin prucaloprida, permanecía asintomático, mejorando las gammagrafías (Tabla 1).

\section{DISCUSIÓN}

Presentamos un niño con gastroparesia que no mejoró con metoclopramida, domperidona, eritromicina y esomeprazol. Esto nos obligó a considerar la prucaloprida, utilizada en niños con estreñimiento, ${ }^{4}$ pero que, además, acelera el vaciamiento gástrico, ${ }^{5-7}$ mejora la acomodación gástrica, ${ }^{10}$ aumenta la sensibilidad a la distensión gástrica ${ }^{10} \mathrm{y}$ acelera el tránsito intestinal. ${ }^{4,6}$

TABla 2. Dosis y tiempo de tratamiento con los medicamentos recibidos previo al inicio del tratamiento con prucaloprida

\begin{tabular}{|c|c|c|c|c|c|c|c|c|c|}
\hline & \multirow[b]{2}{*}{1} & \multicolumn{8}{|c|}{ Días de hospitalización } \\
\hline & & 13 & 19 & 20 & 21 & 25 & 28 & 34 & 43 \\
\hline \multicolumn{10}{|l|}{ Domperidona (dosis: 0,9 mg/kg/ día en tres dosis) } \\
\hline \multicolumn{10}{|l|}{ Eritromicina (dosis: 15 mg/kg/ día en tres dosis) } \\
\hline \multicolumn{10}{|l|}{ Metoclopramida (dosis: 0,6 mg/kg/ día en tres dosis) } \\
\hline \multicolumn{10}{|l|}{ Esomeprazol (dosis: 1 mg/kg/día) } \\
\hline \multicolumn{10}{|l|}{ Polietilenglicol sin electrolitos (dosis: 1 g/kg/ día) } \\
\hline Picosulfato de sodio (dosis: 6 mg/día) & & & & & & & & & \\
\hline
\end{tabular}

TABLA 3. Seguimiento nutricional

\begin{tabular}{|c|c|c|c|c|c|c|c|}
\hline & \multicolumn{3}{|c|}{ Días de hospitalización } & \multirow{2}{*}{$\begin{array}{c}\begin{array}{c}\text { Primer período } \\
\text { de prucaloprida }\end{array} \\
\text { Día } 124\end{array}$} & \multicolumn{3}{|c|}{$\begin{array}{l}\text { Segundo período } \\
\text { de prucaloprida }\end{array}$} \\
\hline & Día 1 & Día 19 & Día 40 & & Día 65 & Día 152 & Día 376 \\
\hline Peso (kg) & 20 & 19,5 & 17,5 & 20 & 20 & 21 & 26 \\
\hline Talla $(\mathrm{cm})$ & 119 & 119 & 119 & 120 & 121,5 & 121,5 & 122 \\
\hline $\operatorname{IMC}\left(\mathrm{kg} / \mathrm{m}^{2}\right)$ & 14,1 & 13,8 & 12,3 & 13,9 & 13,5 & 14,2 & 17,5 \\
\hline IMC/ edad ${ }^{a}$ & $-1,37$ & $-1,68$ & $-3,56$ & $-1,65$ & $-2,14$ & $-1,51$ & 0,38 \\
\hline Talla/edad ${ }^{a}$ & $-1,87$ & $-1,88$ & $-1,93$ & $-2,05$ & $-2,05$ & $-2,34$ & $-2,65$ \\
\hline
\end{tabular}

IMC: índice de masa corporal.

${ }^{a}$ Desviación estándar de acuerdo con las tablas de crecimiento de la Organización Mundial de la Salud. 
La prucaloprida imita el efecto agonista de 5-TH en el receptor $5-\mathrm{HT}_{4}$. $\mathrm{Al}$ estimular los receptores 5- $\mathrm{HT}_{4}$ localizados en el plexo mientérico, se libera acetilcolina y se produce contracción muscular, ${ }^{11}$ mientras que, si se estimulan los localizados en el músculo liso, se genera AMP cíclico y se inhiben las contracciones musculares. ${ }^{12}$ En el antro y cuerpo del estómago, los receptores $5-\mathrm{HT}_{4}$ se encuentran en el plexo mientérico, mientras que en el fondo gástrico se distribuyen en el músculo liso. ${ }^{13} \mathrm{El}$ antro determina el vaciamiento de sólidos ${ }^{14} \mathrm{y}$ el fondo de líquidos. ${ }^{15} \mathrm{El}$ paciente presentaba retardo en el vaciamiento gástrico de sólidos y líquidos. La mejoría con prucaloprida también pudo deberse a una mejoría de la acomodación gástrica, ${ }^{10}$ que es una reducción del tono gástrico con un aumento del volumen fúndico en respuesta a la ingesta de alimentos.

En el primer período de prucaloprida, el GCSI mejoró a los 18 días, un tiempo similar al reportado en otro estudio. ${ }^{7}$ En el segundo período, el tiempo de respuesta fue más demorado, 108 días. Esta diferencia en el tiempo de respuesta puede explicarse por su compromiso nutricional al comenzar el segundo período de prucaloprida o una reacción adversa al esomeprazol; los aumentos de gastrina, secundarios a los inhibidores de la bomba de protones, y la amplitud de las contracciones gástricas provocan un retardo del vaciamiento gástrico. ${ }^{15}$ Veinticinco días después de suspender el esomeprazol, mejoró el GCSI. Los inhibidores de la bomba de protones se usan hasta en el $79 \%$ de los niños con gastroparesia, ${ }^{1}$ por lo que se considera suspenderlos cuando no hay una respuesta adecuada con procinéticos.

Se siguió al paciente con el GCSI y con gammagrafías. Aunque un estudio con niños evidenció que el GCSI no estaba asociado con retardos en el vaciamiento gástrico, presentaba las limitantes de no haber utilizado los criterios de Roma para descartar dispepsia funcional y una muestra pequeña. ${ }^{9}$ La primera gammagrafía muestra asociación con el GCSI. Al realizar la segunda gammagrafía, a pesar de mejoría del GCSI, había compromiso nutricional, que pudo haber influido en los resultados. Al suspender el primer período con prucaloprida, hubo deterioro en la tercera gammagrafía y un reinicio de síntomas, y una respuesta más demorada al tratamiento. No hay claridad del tiempo de tratamiento y se requirió más de un año con prucaloprida para evidenciar mejorías del GCSI y gammagrafías normales.
Este paciente toleró bien la prucaloprida, solo presentó dolor abdominal que mejoró con la disminución de la dosis, sin otros efectos adversos. Consideramos que la prucaloprida podría ser una opción en el manejo de niños con gastroparesia idiopática y que se necesitan estudios en niños para evaluar su seguridad y efectividad.

\section{REFERENCIAS}

1. Rodriguez L, Irani K, Jiang H, Goldstein AM. Clinical presentation, response to therapy, and outcome of gastroparesis in children. J Pediatr Gastroenterol Nutr. 2012; 55(2):185-90.

2. Waseem S, Islam S, Kahn G, Moshiree B, Talley N.Spectrum of gastroparesis in children. J Pediatr Gastroenterol Nutr. 2012; 55(2):166-72.

3. Tack J, Camilleri M, Chang L, Chey WD, et al. Systematic review: cardiovascular safety profile of 5-HT(4) agonists developed for gastrointestinal disorders. Aliment Pharmacol Ther. 2012; 35(7):745-67.

4. Winter HS, Di Lorenzo C, Benninga MA, Gilger MA, et al. Oral prucalopride in children with functional constipation. J Pediatr Gastroenterol Nutr. 2013; 57(2):197-203.

5. Kessing BF, Smout AJ, Bennink RJ, Kraaijpoel N, et al. Prucalopride decreases esophageal acid exposure and accelerates gastric emptying in healthy subjects. Neurogastroenterol Motil. 2014; 26(8):1079-86.

6. Bouras EP, Camilleri M, Burton DD, Thomforde G, et al. Prucalopride accelerates gastrointestinal and colonic transit in patients with constipation without a rectal evacuation disorder. Gastroenterology. 2001; 120(2):354-60.

7. Carbone F, Van den Houte K, Clevers E, Andrews CN, et al. Prucalopride in Gastroparesis: A Randomized PlaceboControlled Crossover Study. Am J Gastroenterol. 2019; 114(8):1265-74.

8. Revicki DA, Rentz AM, Dubois D, Kahrilas P, et al. Development and validation of a patient-assessed gastroparesis symptom severity measure:The Gastroparesis Cardinal Symptom Index. Aliment Pharmacol Ther. 2003; 18(1):141-50.

9. Jericho H, Adams P, Zhang G, Rychlik K, Saps M. Nausea predicts delayed gastric emptying in children. J Pediatr. 2014; 164(1):89-92.

10. Carbone F, Tack J. OP006. The effect of prucalopride on gastric accommodation in healthy volunteers. Neurogastroenterol Motil. 2014; 26(Suppl 1):3-4.

11. Kilbinger $H$, Wolf D. Effects of 5-HT4 receptor stimulation on basal and electrically evoked release of acetylcholine from guinea-pig myenteric plexus. Naunyn Schmiedebergs Arch Pharmacol. 1992; 345(3):270-5.

12. McLean PG, Coupar IM. Stimulation of cyclic AMP formation in the circular smooth muscle of human colon by activation of 5-HT4-like receptors. Br J Pharmacol. 1996; 117(2):238-9.

13. Takada K, Sakurai-Yamashita $Y$, Yamashita K, Kaibara M, et al. Regional difference in correlation of 5-HT4 receptor distribution with cholinergic transmission in the guinea pig stomach. Eur J Pharmacol. 1999; 374(3):489-94.

14. Camilleri M, Malagelada JR, Brown ML, Becker G, Zinsmeister AR. Relation between antral motility and gastric emptying of solids and liquids in humans. Am J Physiol. 1985; 249(5 Pt 1):G580-5.

15. Dozois RR, Kelly KA. Effect of a gastrin pentapeptide on canine gastric emptying of liquids. Am J Physiol. 1971; 221(1):113-7. 